\title{
Factors Associated with Pregnancy Among Filipino Women Aged 15- 19: Results from the 2017 Philippine National Demographic and Health Survey
}

\author{
Veincent Christian Pepito ( $\sim$ vpepito@ateneo.edu ) \\ Ateneo de Manila University Ateneo School of Medicine and Public Health https://orcid.org/0000-0001-5391-3784 \\ Arianna Maever L. Amit \\ Ateneo de Manila University ASMPH: Ateneo de Manila University Ateneo School of Medicine and Public Health \\ Clinton S. Tang \\ Ateneo de Manila University ASMPH: Ateneo de Manila University Ateneo School of Medicine and Public Health \\ Luis Miguel B. Co \\ Ateneo de Manila University ASMPH: Ateneo de Manila University Ateneo School of Medicine and Public Health \\ Neil Andrew K. Aliazas \\ Ateneo de Manila University ASMPH: Ateneo de Manila University Ateneo School of Medicine and Public Health \\ Sarah J. De Los Reyes \\ Ateneo de Manila University ASMPH: Ateneo de Manila University Ateneo School of Medicine and Public Health \\ Raymundo S. Baquiran \\ Ateneo de Manila University ASMPH: Ateneo de Manila University Ateneo School of Medicine and Public Health \\ Lourdes Bernadette S. Tanchanco \\ Ateneo de Manila University ASMPH: Ateneo de Manila University Ateneo School of Medicine and Public Health
}

\section{Research}

Keywords: Pregnancy, physical, emotional, psychosocial

Posted Date: August 24th, 2021

DOI: https://doi.org/10.21203/rs.3.rs-808908/v1

License: (c) (i) This work is licensed under a Creative Commons Attribution 4.0 International License. Read Full License 


\section{Abstract}

Background: Teenage pregnancy is an event known to have physical, emotional, and psychosocial implications. Despite such risks, many teenage Filipino women still have unintended pregnancies. This study aims to identify factors associated with pregnancy among Filipino women aged 15-19.

Methods: We used data from the individual recode of the 2017 Philippine National Demographic and Health Survey. We used logistic regression for survey data to identify determinants associated with teenage pregnancy.

Results: Out of 5,120 respondents, $420(8.56 \%)$ have ever been pregnant. After adjusting for confounding variables, we find that there is strong evidence that belonging to the richer (adjusted odds ratio (aOR): $0.51 ; 95 \%$ Confidence Interval $(\mathrm{Cl}): 0.27,0.97)$ and richest (aOR: $0.45 ; 95 \% \mathrm{Cl}$ : $0.22,0.93)$ socio-economic strata are protective against teenage pregnancy. Accessing the internet at least once a week (aOR: $0.42 ; 95 \% \mathrm{Cl}$ : $0.24,0.74$ ) or almost every day (aOR: $0.45 ; 95 \% \mathrm{Cl}: 0.23,0.86$ ) are also protective against teenage pregnancy. Among the religions, being Protestant (aOR: $0.46 ; 95 \% \mathrm{Cl}: 0.22,0.96)$, or a Muslim (aOR: $0.28 ; 95 \% \mathrm{Cl}: 0.14,0.58$ ) lower the odds of teenage pregnancy as compared to being Roman Catholic. On the other hand, there is strong evidence that just finishing primary education raises the odds of teenage pregnancy by six times (aOR: $6.25 ; 95 \% \mathrm{Cl}: 1.31,29.89$ ) as compared to those who did not have any formal education. A year increase in age also increases the odds of teenage pregnancy by 2.93 times (aOR: $2.93 ; 95 \% \mathrm{Cl}: 2.48,3.46$ ).

Conclusions: These findings highlight the need to implement reproductive health education and contraceptive promotion interventions on a nationwide scale. Promoting internet access through investments in internet coverage and speed may also help in further decrease teenage pregnancy. Urgent action is needed considering the prevalence of teenage pregnancy in the country and its rapid increase due to the COVID-19 pandemic.

\section{Plain English Summary}

Adolescent pregnancy is associated with adverse health, psychosocial, and economic outcomes. As of 2017, the proportion of women aged 15-19 who have begun childbearing in the Philippines is $9 \%$. Thus, we studied what factors are associated with pregnancy among Filipino women aged 15-19. We analysed the 2017 Philippine National Demographic and Health Survey. After controlling for the effect of other variables, there is evidence of a positive association between increasing age and having just primary education with pregnancy for this age group. On the other hand, belonging to higher socio-economic strata, having frequent internet access, and being of the Protestant or Muslim faith lower the odds of teenage pregnancy. These findings highlight the need to strengthen reproductive health education and improve reproductive health awareness among the youth. However, recent evidence shows that reproductive health education per se might be insufficient in preventing teenage pregnancies and should be coupled with interventions to promote usage of modern contraceptives (e.g., condom, pills, implants, etc.) for it to be effective. Investments in internet coverage may also decrease teenage pregnancy and should be scaled up across many areas in the country. Urgent action is also needed considering that teenage pregnancies are on the rise as a result of the COVID-19 pandemic.

\section{Introduction}

Teenage pregnancy, or pregnancy among adolescents, is an event known to have significant physical, emotional, and psychological implications which also predisposes adolescents to several risk factors and health complications (1). Adolescent mothers are more likely to undergo illegal and unsafe abortions which could cause disease or even death $(2,3)$. In addition, mothers of this age group also have a higher risk of developing several health complications including eclampsia, puerperal endometritis, and systemic infections when compared to older mothers. Children from these younger mothers were also observed to be more likely to have low birth weight, preterm birth, and develop severe neonatal conditions than children born to older mothers (4-6). In addition to the potential health complications stemming from early pregnancy, teenage pregnancy also creates a lasting impact on a woman's social and economic standing. The social consequences of bearing a child before the age of 18 include greater risk of experiencing violence in their relationship with their spouse or partner on top of the social stigma and rejection from their respective families and peers. Career opportunities can also become limited as most young women are forced to drop out of school as a result of their pregnancies $(7,8)$.

Almost 21 million adolescent girls aged 15 to 19 in developing regions worldwide become pregnant every year with approximately half of them giving birth (9). From 1993 to 2013, pregnancy rates among Filipino women aged 15-19 steadily increased from 6.5-10\% (1, 10). In 2017, the Philippines had reported that $9 \%$ of teenage women between the ages of 15 and 19 have begun childbearing; $7 \%$ have had a live birth, and $2 \%$ are pregnant with their first child $(11,12)$. In addition, the country's high maternal mortality ratio is thought to be partly due to unsafe abortions of unwanted adolescent pregnancies $(2,3)$. Despite the passage of the country's Reproductive Health law $(13)$, there remains a strong conservative influence and belief that perceive contraceptives as improper for adolescent use, which preclude agreement with World 
Health Organization recommendations on reproductive health (3). In addition to policy issues, socio-demographic factors were also found to contribute to the burden of adolescent pregnancy in the country $(14,15)$. Teenage girls with higher educational attainment and women from wealthier households were found to be less likely to be pregnant than women with lower educational attainment and women from poorer households. In addition, contraceptive use was found to be associated with adolescent pregnancy, but is more likely due to improper use and/or usage after pregnancy (15). Another study on repeated pregnancy in the country found that while repeated pregnancy has decreased on older adolescents, it has remained constant among those who aged 15-18 for two decades. The same study found that adolescents from poorer households are more likely to have repeated pregnancy as well (14).

In other countries, studies on the determinants of teenage pregnancy have been conducted. Quantitative studies have found that age, contraceptive use, socio-economic status, physical violence, residence in rural areas, history of teenage pregnancy of mother and sister, lack of communication with parents on sexual health, and marital status have all been found to be associated with teenage pregnancy (16-21). In a qualitative study on the factors affecting teenage pregnancy in rural Lao PDR, liberal attitudes to pre-marital sexual intercourse, early marriage and pregnancy, incomplete knowledge of sexual and reproductive health, and limited access to appropriate services (22). One review on the topic concludes that a host of sociocultural, environmental, and economic factors (e.g., peer influence, sexual advances from adult males, etc.), individual factors (e.g., substance abuse, mobile phone use), and health service-related factors (e.g., cost of contraceptives, inadequate manpower of healthcare facilities, etc.) contribute to adolescent pregnancy in sub-Saharan Africa (23). Similar factors were also found in another review, but the same review also concludes that social cohesion in communities, cultural background, mass media access, and religion also have strong associations with teenage pregnancy (24).

While previous studies have examined the determinants of teenage pregnancy in the Philippines $(14,15,25)$, the few covariates they have considered would mean possible residual confounding and fewer avenues for intervention. More importantly, they do not consider the possible effect of more recent reproductive health policies implemented in the country, with Executive Order No. 12, passed in 2017, aims to increase contraceptive use in the Philippines $(13,26)$. However, even with the passage of these laws, the burden of teenage pregnancy continues to be prevalent in the country, with the country's Population Commission estimating that 40-50 Filipino girls give birth every week (27). In line with calls for further studies on teenage pregnancy in the Philippines, this paper aims to identify factors associated with pregnancy among Filipino women aged 15-19 in the 2017 Philippine National Demographic and Health Survey.

\section{Methods}

\section{Study population and sampling method}

The 2017 Philippine NDHS is a nationally representative survey whose primary objective is to provide up-to-date estimates of basic demographic and health indicators. The survey utilized a two-stage stratified design utilizing the Master Sampling Frame designed by the Philippine Statistics Authority. The strata used were 117 major sampling domains in the country (81 provinces, 33 highly urbanized cities and 3 special areas). The first stage sampling involved the systematic selection of 1,250 primary sampling units throughout the entire Philippines. Such primary sampling units can be barangays (Philippine equivalent of village), a portion of a large barangay or two or more adjacent small barangays. Once these primary sampling units were selected, either 20 or 26 housing units were systematically random sampled. Nonreplacement sampling was utilized to prevent bias. Survey weights were then computed. All women aged 15-49 years old who were either permanent residents of the selected households or visitors who stayed in the households the night before the survey were eligible to be interviewed. However, we will only include women aged 15-19 for this analysis. Other details of the sampling method utilized by the survey is available in its published manuscript (12).

\section{Data collection, definition of variables, and data management}

Two questionnaires administered using tablet computers by trained field interviewers were used for the 2017 NDHS. The questionnaires were translated to six local languages commonly spoken throughout the Philippines: Tagalog, Cebuano, Ilokano, Bikol, Hiligaynon, and Waray and were then pre-tested. Actual data collection was done between August 14 to October 27, 2017. Data processing began shortly after initiation of data collection, and a clean dataset was prepared by late 2017 (12). For this analysis, we will use the Individual Recode dataset of the 2017 Philippine NDHS.

The survey collected data on socio-demographic variables, fertility levels and preferences, awareness and use of family planning methods, breastfeeding, maternal and child health, child mortality, awareness and behavior regarding HIV/AIDS, women's empowerment, domestic violence, and other health-related issues (12). For this analysis, however, we will only make use of data on socio-demographic, awareness and use of family planning methods, and awareness and behaviors regarding HIV/AIDS. Specifically, the outcome variable for this analysis is teenage pregnancy. A respondent is considered to have the outcome if she is either pregnant at the time of the interview, or has given birth at least once; otherwise, she will be considered as not having the outcome. Exposure variables include known determinants of teenage 
pregnancy include age, socio-economic status, educational attainment, contraceptive use, domicile, physical violence, marital status, religion, HIV knowledge, and access to various forms of media (14-25). In addition, we also consider the following as exposure variables: husband/partner's education level, whether it is justifiable for a wife to ask husband to use condom if he has STI, and whether the respondent can ask partner to use condom, decision-maker for using contraception, reading about contraception in the internet, heard about family planning on radio, tv, newspaper/magazine, and text message, tobacco use, alcohol use, age of partner, number of lifetime sexual partners, and household size.

The HIV knowledge questions were aggregated from the answers of respondents on eight yes or no items from the NDHS: (a) reduce risk of getting HIV by having sex with only one partner who has no other partners; (b) reducing risk of getting HIV by always using condom; (c) can get HIV from mosquito bites; (d) can get HIV by sharing food with somebody; (e) a healthy looking person can have HIV; (f) HIV can be transmitted during pregnancy; (g) HIV can be transmitted during delivery; (h) HIV transmitted by breastfeeding. For each item a respondent gets correctly, the respondent gets one point. The points from each item were added to comprise the HIV knowledge score, thus, those who have a higher HIV knowledge score have greater HIV knowledge as compared to those who have low knowledge. We also recoded some categorical variables to ensure that each category would have sufficient respondents.

\section{Data Analysis}

All data management and analyses were carried out in Stata 14.0 IC (28) and we used a level of significance of 0.05 (29). After data cleaning and recoding, we declared our dataset as survey data using the weighting for the entire survey as sampling weight. All our subsequent analyses are weighted, except for analyses that do not have an option for weighting. Thus, proportions, means odds ratios, and p-values, except for tests of normality and rank-sum tests, were weighted. However, we still showed the number of observations, which are unweighted. Once we declared our dataset as survey data, we ran descriptive statistics for all variables of interest. We identified the proportions and frequencies of the categories for each of our categorical variables. For our continuous variables, we described their range, distribution, and the appropriate measure of central tendency. We also described the number of respondents with missing data for each variable under study.

We then cross-tabulated the different exposure variables with our outcome variable. We note the p-values of the Pearson's chi-square test and crude odds ratios. For our continuous exposure variables, we performed either Wald test for normally distributed variables or rank-sum test for skewed variables, to assess their association with the outcome. Once we have done the cross-tabulations, we ran a correlation matrix to assess potential collinearity between variables. If variables will have a correlation coefficient of $>0.70$, one of the variables were removed from the analyses. Prior to doing multivariate analyses, we also excluded respondents with those who have missing data in any of the variables of interest by using Stata's subpop function to ensure that estimates and standard errors are computed correctly.

We used logistic regression for survey data to estimate the crude and adjusted estimates of the associations between the different exposure variables and consistent condom use. In choosing the variables to include our final model, we first categorized variables into proximal and distal risk factors. Proximal risk factors are risk factors that are closer to the outcome, while distal risk factors are risk factors that are more "upstream" and usually affect the outcome indirectly. In building our model, we first fit distal factors that are strongly associated with consistent condom use from our cross-tabulations. Then we include the remaining distal factors found in literature (that did not show a strong association with our outcome in the cross-tabulations) into our final regression model. Once we have the distal factors in our model, we fit the proximal risk factors who were associated with the outcome in our cross-tabulations. Then we include the proximal risk factors that are found in the literature (that did not show a strong association with our outcome in the cross-tabulation) into our final regression model. Variables that will cause unstable estimates will be excluded from the model. Effect measure modification will be formally assessed using Stata's contrast command on variables that may possibly show joint effects.

\section{Results}

There were 5,120 women aged 15-19 in the 2017 Philippine National Demographic and Health Survey. Majority (77.5\%) have achieved secondary education, and 53.53\% report living in rural areas. More than $90 \%$ report never being in union and $78.17 \%$ reported being Roman Catholics. Around $0.68 \%$ of respondents have experienced some form of physical violence. Regarding contraceptive use and intent, $54.24 \%$ do not intend to use contraceptives at all, followed by $42.2 \%$ reporting not using contraceptives now but intending to use it in the future. Less than $1 \%$ use traditional forms of contraception (e.g., withdrawal, calendar method, etc.) while around $2.5 \%$ use modern forms of contraception (e.g., male/female condom, implants, oral contraceptive pills, etc.). When presented with a hypothetical scenario whether the wife is justified in asking her husband to use condoms if he has a known sexually transmitted infection (STI), 68.33\% responded "yes", while the rest responded otherwise. There are very few responses for questions on agency; with only $5.35 \%$ of respondents saying that they can ask their partners to use condoms, and 3.20\% saying they cannot. Decision-making for contraception use also showed significant missing data, but some $2.29 \%$ of respondents said that it is a joint decision between them and their partner. Some $44 \%$ of respondents have accessed information on contraception from the internet, $25 \%$ have heard information about contraception through the radio, 55\% of respondents have heard about

Page $4 / 15$ 
contraception via television, $15 \%$ have read about contraception in the newspapers and magazines, and only $6 \%$ have received information on contraception via short messaging service (SMS). Around $8.6 \%$ of respondents have ever been or is pregnant at the time of data collection.

Without adjusting for confounding variables, we find that there is strong evidence that wealth index, educational attainment of respondent, consistent condom use, contraceptive use and intention, domicile, current marital status, frequency of reading newspaper or magazine, frequency of watching television, frequency of internet use, feeling that wife is justified to ask husband to use condom, and accessing information on contraception via the internet were all associated with teenage pregnancy. (Table 1). Moreover, age of respondent are also associated with teenage pregnancy (Table 2). Despite not having shown significant associations with the outcome in this analysis, religion and HIV knowledge will still be included in the multivariate analyses as these has been identified as determinants of the outcome in previous studies (13-24). 
Table 1

Crude associations of categorical exposure variables with experiencing teenage pregnancy $(n=5,120)$.

\begin{tabular}{|c|c|c|c|c|c|}
\hline & $\begin{array}{l}\text { Never experienced } \\
\text { teenage pregnancy }\end{array}$ & $\begin{array}{l}\text { Experienced } \\
\text { teenage pregnancy }\end{array}$ & $\begin{array}{l}\mathrm{p}- \\
\text { value }\end{array}$ & $\begin{array}{l}\text { Crude OR } \\
\text { (with 95\% Cl) }\end{array}$ & $\begin{array}{l}\text { p-value } \\
\text { of OR }\end{array}$ \\
\hline \multicolumn{6}{|l|}{ Wealth index } \\
\hline Poorest & $1046(85.2)$ & $164(14.8)$ & \multirow{5}{*}{$\begin{array}{l}< \\
0.01\end{array}$} & 1 (baseline) & \\
\hline Poorer & $1106(90.1)$ & $107(9.9)$ & & $0.63(0.46,0.88)$ & 0.01 \\
\hline Middle & 929 (88.9) & $81(11.1)$ & & $0.72(0.48,1.09)$ & 0.12 \\
\hline Richer & $851(95.0)$ & $43(5.0)$ & & $0.30(0.19,0.49)$ & $<0.01$ \\
\hline Richest & $768(96.8)$ & $25(3.2)$ & & $0.19(0.10,0.37)$ & $<0.01$ \\
\hline \multicolumn{6}{|c|}{ Educational attainment of respondent } \\
\hline No education & $13(87.1)$ & $3(12.9)$ & \multirow{4}{*}{$\begin{array}{l}< \\
0.01\end{array}$} & 1 (baseline) & \\
\hline Primary education & $262(68.2)$ & $104(31.8)$ & & $\begin{array}{l}3.15(0.76 \\
13.04)\end{array}$ & 0.11 \\
\hline Secondary education & 3681 (92.5) & $271(7.5)$ & & $0.55(0.14,2.21)$ & 0.40 \\
\hline Higher & $744(95.5)$ & $42(4.5)$ & & $0.32(0.07,135)$ & 0.12 \\
\hline \multicolumn{6}{|l|}{ Consistent condom use } \\
\hline Does not use condoms & $155(27.4)$ & $366(72.6)$ & \multirow{3}{*}{$\begin{array}{l}< \\
0.01\end{array}$} & 1 (baseline) & \\
\hline Inconsistently used condoms & $3(81.2)$ & $1(18.8)$ & & $0.09(0.01,0.90)$ & 0.04 \\
\hline Consistently used condoms & $17(79.0)$ & $3(21.0)$ & & $0.10(0.02,0.53)$ & 0.01 \\
\hline Missing & $4,525(98.8)$ & $50(1.2)$ & & & \\
\hline \multicolumn{6}{|l|}{ Contraceptive use and intention } \\
\hline Does not intend to use & $2,738(97.1)$ & $76(2.9)$ & \multirow{4}{*}{$\begin{array}{l}< \\
0.01\end{array}$} & 1 (baseline) & \\
\hline Non-user - intends to use later & $1,927(90.5)$ & $191(9.5)$ & & $3.45(2.36,5.07)$ & $<0.01$ \\
\hline Using traditional method & $19(43.3)$ & $19(56.7)$ & & $\begin{array}{l}43.15(18.56 \\
100.33)\end{array}$ & $<0.01$ \\
\hline Using modern method & $4(2.6)$ & $127(97.4)$ & & $\begin{array}{l}1252.836 \\
(377.77 \\
4154.86)\end{array}$ & $<0.01$ \\
\hline Missing & $12(59.8)$ & $7(40.2)$ & & & \\
\hline \multicolumn{6}{|c|}{ Type of place of residence (Domicile) } \\
\hline Urban & $1,587(93.2)$ & $115(6.8)$ & \multirow[t]{2}{*}{0.01} & 1 (baseline) & \\
\hline Rural & 3,113 (89.9) & $305(10.1)$ & & $1.53(1.11,2.12)$ & 0.01 \\
\hline \multicolumn{6}{|l|}{ Physical violence } \\
\hline No & $56(19.8)$ & $203(80.3)$ & \multirow[t]{2}{*}{0.10} & 1 (baseline) & \\
\hline Yes & $6(9.5)$ & $38(90.5)$ & & $2.35(0.82,6.72)$ & 0.11 \\
\hline Missing & 4,638 (96.2) & $179(3.8)$ & & & \\
\hline \multicolumn{6}{|l|}{ Current marital status } \\
\hline Never in union & $4,605(98.9)$ & $55(1.1)$ & \multirow{3}{*}{$\begin{array}{l}< \\
0.01\end{array}$} & 1 (baseline) & \\
\hline Married & $23(21.2)$ & $86(78.9)$ & & $\begin{array}{l}323.57(163.26 \\
641.29)\end{array}$ & $<0.01$ \\
\hline Living with partner & $62(16.4)$ & $260(83.6)$ & & $\begin{array}{l}440.93(253.20 \\
767.84)\end{array}$ & $<0.01$ \\
\hline
\end{tabular}




\begin{tabular}{|c|c|c|c|c|c|}
\hline & $\begin{array}{l}\text { Never experienced } \\
\text { teenage pregnancy }\end{array}$ & $\begin{array}{l}\text { Experienced } \\
\text { teenage pregnancy }\end{array}$ & $\begin{array}{l}\mathrm{p}- \\
\text { value }\end{array}$ & $\begin{array}{l}\text { Crude OR } \\
\text { (with 95\% Cl) }\end{array}$ & $\begin{array}{l}\text { p-value } \\
\text { of OR }\end{array}$ \\
\hline $\begin{array}{l}\text { Widowed/Divorced/No longer living together } \\
\text { or separated }\end{array}$ & $10(23.5)$ & $19(76.5)$ & & $\begin{array}{l}282.36(105.30 \\
757.06)\end{array}$ & $<0.01$ \\
\hline \multicolumn{6}{|l|}{ Religion } \\
\hline Roman Catholic & 3318 (91.1) & $317(8.9)$ & \multirow[t]{7}{*}{0.08} & 1 (baseline) & \\
\hline Protestant & $456(93.2)$ & $30(6.9)$ & & $0.75(0.45,1.27)$ & 0.29 \\
\hline Iglesia ni Cristo & $135(94.5)$ & $7(5.5)$ & & $0.60(0.23,1.57)$ & 0.30 \\
\hline Aglipay & $63(82.8)$ & $5(17.2)$ & & $2.13(0.58,7.78)$ & 0.26 \\
\hline Islam & $493(93.1)$ & $37(6.9)$ & & $0.76(0.47,1.24)$ & 0.27 \\
\hline Other Christian & $161(96.2)$ & $11(3.8)$ & & $0.41(0.19,0.88)$ & 0.02 \\
\hline Other & $74(82.1)$ & $13(17.9)$ & & $2.23(0.90,5.56)$ & 0.09 \\
\hline \multicolumn{6}{|l|}{ Frequency of reading newspaper or magazine } \\
\hline Not at all & $2132(88.9)$ & $246(11.1)$ & \multirow[t]{3}{*}{0.02} & 1 (baseline) & \\
\hline Less than once a week & $1855(92.4)$ & $143(7.6)$ & & $0.66(0.49,0.90)$ & 0.01 \\
\hline At least once a week & $713(95.8)$ & $31(4.3)$ & & $0.36(0.18,0.71)$ & $<0.01$ \\
\hline \multicolumn{6}{|l|}{ Frequency of listening to radio } \\
\hline Not at all & $1,390(91.1)$ & $128(8.9)$ & \multirow[t]{3}{*}{0.26} & 1 (baseline) & \\
\hline Less than once a week & $1,739(92.7)$ & $144(7.4)$ & & $0.81(0.55,1.19)$ & 0.28 \\
\hline At least once a week & $1,571(90.4)$ & $148(9.6)$ & & $1.08(0.73,1.60)$ & 0.70 \\
\hline \multicolumn{6}{|l|}{ Frequency of watching television } \\
\hline Not at all & $385(86.7)$ & $47(13.3)$ & \multirow[t]{3}{*}{0.03} & 1 (baseline) & \\
\hline Less than once a week & $828(89.8)$ & $89(10.2)$ & & $0.74(0.43,1.30)$ & 0.30 \\
\hline At least once a week & $3,487(92.1)$ & $284(7.9)$ & & $0.56(0.35,0.88)$ & 0.01 \\
\hline \multicolumn{6}{|l|}{ Frequency of using internet last month } \\
\hline Not at all & $817(81.7)$ & $147(18.2)$ & \multirow{4}{*}{$<.01$} & 1 (baseline) & \\
\hline Less than once a week & $507(83.5)$ & $68(16.5)$ & & $0.88(0.57,1.37)$ & 0.58 \\
\hline At least once a week & $1,401(93.7)$ & $97(6.3)$ & & $0.30(0.21,0.43)$ & $<0.01$ \\
\hline Almost every day & $1,975(94.5)$ & $108(5.5)$ & & $0.26(0.17,0.38)$ & $<0.01$ \\
\hline \multicolumn{6}{|l|}{ Husband/Partner's educational attainment } \\
\hline No education & $3(37.1)$ & $4(62.9)$ & \multirow[t]{4}{*}{0.37} & 1 (baseline) & \\
\hline Primary education & $29(21.3)$ & $115(78.7)$ & & $\begin{array}{l}2.17(0.46 \\
10.24)\end{array}$ & 0.33 \\
\hline Secondary education & $45(14.8)$ & $189(85.2)$ & & $\begin{array}{l}3.40(0.81 \\
14.33)\end{array}$ & 0.10 \\
\hline Higher & $8(16.1)$ & $38(83.9)$ & & $\begin{array}{l}3.07(0.54 \\
17.48)\end{array}$ & 0.21 \\
\hline Missing & $4615(98.4)$ & $74(1.6)$ & & & \\
\hline \multicolumn{6}{|l|}{$\begin{array}{l}\text { Wife justified asking husband to use condom } \\
\text { if he has STI }\end{array}$} \\
\hline No & $1,571(94.1)$ & $85(6.0)$ & \multirow[t]{2}{*}{0.01} & 1 (baseline) & \\
\hline Yes & $3,129(90.2)$ & $335(9.8)$ & & $1.71(1.17,2.50)$ & 0.01 \\
\hline
\end{tabular}




\begin{tabular}{|c|c|c|c|c|c|}
\hline & $\begin{array}{l}\text { Never experienced } \\
\text { teenage pregnancy }\end{array}$ & $\begin{array}{l}\text { Experienced } \\
\text { teenage pregnancy }\end{array}$ & $\begin{array}{l}\mathrm{p}- \\
\text { value }\end{array}$ & $\begin{array}{l}\text { Crude OR } \\
\text { (with 95\% Cl) }\end{array}$ & $\begin{array}{l}\text { p-value } \\
\text { of OR }\end{array}$ \\
\hline \multicolumn{6}{|c|}{ Respondent can ask partner to use a condom } \\
\hline No & $32(18.8)$ & $113(81.2)$ & \multirow[t]{2}{*}{0.60} & \multicolumn{2}{|l|}{1 (baseline) } \\
\hline Yes & $53(16.3)$ & $233(83.7)$ & & $1.19(0.61,2.33)$ & 0.60 \\
\hline Missing & $4,615(98.4)$ & $74(1.6)$ & & & \\
\hline \multicolumn{6}{|c|}{ Decision maker for using contraception } \\
\hline Mainly respondent & $1(2.0)$ & $23(98.0)$ & \multirow[t]{3}{*}{0.42} & 1 (baseline) & \\
\hline Mainly husband/ partner & $3(10.1)$ & $11(89.9)$ & & $0.18(0.02,2.14)$ & 0.17 \\
\hline Joint decision & $9(5.6)$ & $115(94.4)$ & & $0.34(0.04,3.10)$ & 0.34 \\
\hline Missing & $4687(94.2)$ & $271(5.9)$ & & & \\
\hline \multicolumn{6}{|c|}{$\begin{array}{l}\text { Read information about contraception on the } \\
\text { internet }\end{array}$} \\
\hline No & $2798(90.1)$ & $290(9.9)$ & \multirow[t]{2}{*}{0.01} & 1 (baseline) & \\
\hline Yes & $1902(93.2)$ & $130(6.8)$ & & $0.66(0.47,0.92)$ & 0.01 \\
\hline \multicolumn{6}{|c|}{$\begin{array}{l}\text { Heard about family planning on radio last few } \\
\text { months }\end{array}$} \\
\hline No & $3533(91.9)$ & $287(8.1)$ & \multirow[t]{2}{*}{0.16} & 1 (baseline) & \\
\hline Yes & $1167(90.1)$ & $133(9.9)$ & & $1.24(0.91,1.68)$ & 0.17 \\
\hline \multicolumn{6}{|c|}{$\begin{array}{l}\text { Heard about family planning on TV last few } \\
\text { months }\end{array}$} \\
\hline No & 2259 (91.5) & $193(8.5)$ & \multirow[t]{2}{*}{0.89} & 1 (baseline) & \\
\hline Yes & 2441 (91.4) & 227 (8.6) & & $1.02(0.75,1.40)$ & 0.89 \\
\hline \multicolumn{6}{|c|}{$\begin{array}{l}\text { Read about family planning in } \\
\text { newspaper/magazine last few months }\end{array}$} \\
\hline No & 4062 (91.1) & 378 (8.9) & \multirow[t]{2}{*}{0.26} & 1 (baseline) & \\
\hline Yes & $638(93.4)$ & $42(6.6)$ & & $0.72(0.41,1.28)$ & 0.26 \\
\hline \multicolumn{6}{|c|}{$\begin{array}{l}\text { Read about family planning text messages on } \\
\text { mobile phone }\end{array}$} \\
\hline No & 4487 (91.5) & $390(8.5)$ & \multirow[t]{2}{*}{0.67} & 1 (baseline) & \\
\hline Yes & $213(90.1)$ & $30(9.9)$ & & $1.18(0.55,2.54)$ & 0.67 \\
\hline
\end{tabular}

Table 2

Crude association of continuous exposure variables with teenage pregnancy.

\begin{tabular}{|c|c|c|c|c|c|c|c|}
\hline & Range & Mean & Median & Distribution & $\begin{array}{l}\text { p-val of } \\
\text { Ranksum }\end{array}$ & $\begin{array}{l}\text { Crude OR } \\
\text { (with 95\% Cl) }\end{array}$ & p-val \\
\hline Age of respondent $(n=5,120)$ & $\begin{array}{l}15- \\
19\end{array}$ & 16.98 & 17 & Even & $<0.01$ & $\begin{array}{l}2.24(1.97 \\
2.54)\end{array}$ & $\begin{array}{l}< \\
0.01\end{array}$ \\
\hline HIV knowledge $(n=4,464)$ & $0-8$ & 4.58 & 5 & Left-skewed & 0.37 & $\begin{array}{l}1.02(0.94 \\
1.12)\end{array}$ & 0.57 \\
\hline Age of partner $(n=541)$ & $\begin{array}{l}15- \\
58\end{array}$ & 22.94 & 22 & $\begin{array}{l}\text { Right- } \\
\text { skewed }\end{array}$ & 0.06 & $\begin{array}{l}1.08(1.02 \\
1.16)\end{array}$ & 0.02 \\
\hline $\begin{array}{l}\text { Total lifetime number of sex partners }(n= \\
622)\end{array}$ & $1-95$ & 1.34 & 1 & $\begin{array}{l}\text { Right- } \\
\text { skewed }\end{array}$ & 0.06 & $\begin{array}{l}1.01(0.98 \\
1.04)\end{array}$ & 0.53 \\
\hline Number of household members $(n=5,120)$ & $1-21$ & 5.87 & 6 & $\begin{array}{l}\text { Right- } \\
\text { skewed }\end{array}$ & 0.98 & $\begin{array}{l}1.07(1.02 \\
1.13)\end{array}$ & 0.01 \\
\hline
\end{tabular}


Table 3

Association of socio-demographic variables and select sexual health variables with teenage pregnancy $(n=5,101)$.

Adjusted odds ratio and $95 \%$ Confidence interval p-value

Wealth index

Poorest

1 (baseline)

Poorer

$0.80(0.50,1.27)$

0.35

Middle class

$1.06(0.63,1.80)$

0.82

Richer

$0.51(0.27,0.97)$

0.04

Richest

$0.45(0.22,0.93)$

0.03

Highest educational attainment of respondent

None

1 (baseline)

Primary education

$6.25(1.31,29.89)$

0.02

Secondary education

$1.37(0.32,5.80)$

0.67

Higher

$0.25(0.06,1.16)$

0.08

Internet access

Not at all

1 (baseline)

Less than once a week

$0.99(0.54,1.82)$

0.98

At least once a week

$0.42(0.24,0.74)$

Almost every day

$0.45(0.23,0.86)$

0.02

Age $^{\mathrm{b}}$

$2.93(2.48,3.46)$

Domicile

Urban

1 (baseline)

Rural

$1.17(0.76,1.80)$

0.47

Frequency of reading newspapers or magazines

Not at all

1 (baseline)

Less than once a week

$0.94(0.64,1.39)$

0.76

At least once a week

$0.66(0.36,1.23)$

0.20

Frequency of watching television

Not at all

1 (baseline)

Less than once a week

$1.12(0.48,2.63)$

0.80

At least once a week

$1.06(0.51,2.20)$

0.89

Religion

Roman Catholic

1 (baseline)

Protestant

$0.46(0.22,0.96)$

0.04

Iglesia ni Cristo

$0.51(0.21,1.21)$

0.13

Aglipay

$1.12(0.35,3.53)$

0.85

Islam

$0.28(0.14,0.58)$

$<0.01$

a Adjusted for other variables in the table.

${ }^{b}$ Common odds ratio representing increase in odds of teenage pregnancy per unit increase in the variable. 


\begin{tabular}{|c|c|c|}
\hline & Adjusted odds ratio ${ }^{a}$ and $95 \%$ Confidence interval & p-value \\
\hline Other Christian & $0.44(0.19,1.00)$ & 0.05 \\
\hline Other & $2.39(0.82,6.92)$ & 0.11 \\
\hline \multicolumn{3}{|c|}{ Wife justified asking husband to use condom if he has STI } \\
\hline No & 1 (baseline) & \\
\hline Yes & $1.73(1.08,2.77)$ & 0.02 \\
\hline \multicolumn{3}{|c|}{ Read information about contraception on the internet } \\
\hline No & 1 (baseline) & \\
\hline Yes & $0.93(0.60,1.43)$ & 0.74 \\
\hline HIV knowledge ${ }^{b}$ & $1.03(0.92,1.15)$ & 0.63 \\
\hline \multicolumn{3}{|c|}{ a Adjusted for other variables in the table. } \\
\hline${ }^{b}$ Common odds & ge pregnancy per unit increase in the variable. & \\
\hline
\end{tabular}

Among the variables in the study, we detected correlation between civil status and the outcome variable, and so we will no longer include civil status in multivariate analysis $(r=0.78)$. We also noticed that there is separation resulting from the inclusion of contraception use and intention into the model, so we also exclude it from multivariate analysis. We also note that many important variables, such as age of partner, consistent condom use, educational attainment of husband/partner, whether respondent can ask partner to use a condom, experiencing physical violence, and decision-maker for using contraception, have significant missing data $(>80 \%)$ and including them in multivariate analyses would lead to unstable estimates. Thus, we exclude these variables from multivariate analyses. Among the remaining variables, we classified wealth index, educational attainment of respondent, frequency of reading newspapers or magazine, watching television, or using internet, age of respondent, religion, and domicile as distal variables. Contraceptive use and initiation, current marital status, the belief that the wife is justified to ask his husband to use condoms if he has an STI, reading information about contraception on the internet, hearing about family planning on radio in the past few months, and HIV knowledge are classified as proximal variables. Prior to multivariate analyses, we precluded respondents with no complete data in any of the remaining proximal and distal variables of interest. As a result, we have excluded 646 respondents and had an effective sample size of $4,464(90.4 \%)$.

After adjusting for confounding variables, we find that there is strong evidence that belonging to the richer (adjusted odds ratio (aOR): 0.51; $95 \%$ Confidence Interval $(\mathrm{Cl}): 0.27,0.97)$ and richest (aOR: $0.45 ; 95 \% \mathrm{Cl}: 0.22,0.93)$ socio-economic strata are protective against teenage pregnancy. Accessing the internet at least once a week (aOR: $0.42 ; 95 \% \mathrm{Cl}: 0.24,0.74)$ or almost every day (aOR: $0.45 ; 95 \% \mathrm{Cl}: 0.23,0.86)$ are also protective against teenage pregnancy. Among the religions, being Protestant (aOR: $0.46 ; 95 \% \mathrm{Cl}: 0.22,0.96)$, or a Muslim (aOR: $0.28 ; 95 \%$ $\mathrm{Cl}: 0.14,0.58)$ lower the odds of teenage pregnancy as compared to being Roman Catholic. On the other hand, there is strong evidence that just finishing primary education raises the odds of teenage pregnancy by six times (aOR: $6.25 ; 95 \% \mathrm{Cl}: 1.31,29.89)$ as compared to those who did not have any formal education. A year increase in age also increases the odds of teenage pregnancy by 2.93 times (aOR: $2.93 ; 95 \% \mathrm{Cl}$ : $2.48,3.46)$. There is also no effect measure modification between frequency of internet access and accessing information on contraceptives via the internet on teenage pregnancy $(p=0.67)$.

\section{Discussion}

Around $8.6 \%$ of Filipino women aged 15-19 have been or is currently pregnant. Coverage of contraception information vary widely according to media type, ranging from $5 \%$ via short messaging service to $55 \%$ via television. After adjusting for confounding variables, there is evidence of a positive association between increasing age and having just primary education with teenage pregnancy. On the other hand, belonging to higher socio-economic strata, having frequent internet access, and being of the Protestant or Muslim faith lower the odds of teenage pregnancy.

In analyses of previous NDHS in the Philippines, better socio-economic status and higher educational attainment was found to protect against teenage pregnancy (15). Similar trends can be observed for the current analysis, although the evidence of association for the protective effect of education is borderline significant. Such minor differences may be explained by secular changes which may have transpired in the four years between the data collection of the previous NDHS and the NDHS used for this analyses $(10,12)$, which would include greater internet coverage and the full implementation of the country's K-to-12 education policy. Moreover, significant reproductive health policy developments such as greater implementation of the country's reproductive health law, which was still recently passed as of the previous NDHS, and the 
implementation of Executive Order No. 12 which aims to improve the provision of family planning methods regardless of background $(26,30)$, might have also affected how these variables are associated with teenage pregnancy. Another possible difference might be attributable to differences in study methodology: the previous analyses included respondents aged 20-24 years old with the justification that this population group are no longer at risk of having adolescent pregnancies, and would thus give a clear picture of the overall risk of developing adolescent pregnancies as compared to studying respondents aged $15-19$, as was done in this analysis (15). Another difference is in how the covariates were selected in the studies' respective modelling strategies. The previous analyses only assessed for the effect of relatively few sociodemographic covariates and used stepwise regression methods, which could mean that the effect of other variables known to affect the outcome may not have been sufficiently adjusted for in the multivariate model. This analysis considered a greater number of possible exposure variables and controlled for as many known determinants of the outcome as possible. Such variable selection strategies leads to better control of confounding at the expense of parsimony (31).

The strong evidence of positive association between finishing just primary education and teenage pregnancy highlights the need to further strengthen reproductive health education even at the primary level. The country's Reproductive Health Law contains specific provisions on comprehensive reproductive health education throughout the K-12 education curriculum $(30,32,33)$. However, there may be a need to invest in the re-training of teachers as there are some teachers who have negative attitudes on reproductive health education, which could lead to poorer outcomes for students who did not receive it properly. Current initiatives led by the private sector to improve provision of reproductive health education by engaging both teachers and local chief executives is a step in the right direction (34), but it needs to be scaled-up and institutionalized by the national government considering that teenage pregnancy is prevalent nationwide $(11,14,25)$. A Cochrane review of interventions to prevent unintended pregnancies among adolescents posits that educational interventions, on its own, were unlikely to significantly delay the initiation of sexual intercourse; together with contraceptive-promoting interventions, however, it appears to reduce unintended pregnancy among adolescents (35). Thus, reproductive health education might just be insufficient in preventing teenage pregnancy but should also be coupled with contraceptive-promoting interventions, such as contraception education and provision of free, unlimited contraception. Such interventions are necessary to ensure that young women have adequate knowledge about sexual and reproductive health to prevent them from having unwanted pregnancies.

Two things from the univariate analyses remain to be causes of concern: (1) the low proportion of women aged 15-19 using modern forms of contraception, (2) the positive associations of using both traditional and modern contraceptive methods with teenage pregnancy. The positive associations between contraceptive use and teenage pregnancy are counter intuitive. Previous studies have noted similar counter intuitive results as well, and have attributed such to reverse causality, considering that women who previously had an unwanted pregnancy might opt to use contraceptive methods to prevent further pregnancies. Alternatively, this could mean that these women have been using ineffective contraception methods, as in the case for traditional methods, or have been using these contraceptions incorrectly $(15,42-44)$. In any case, these findings highlight the need to educate adolescents on modern contraception methods and their proper use considering that the benefits of modern contraception, especially consistent condom use, prevent unwanted pregnancies and transmission of STIs, including HIV $(45,46)$. This is especially important in tailoring contraception-promotion interventions to accompany comprehensive reproductive health education interventions.

Age was found to be positively associated with teenage pregnancy, which has been consistent with previous research conducted in the Philippines and elsewhere (15-23). This study also finds that certain religions lower the odds of teenage pregnancy; specifically, adhering to Islam and Protestantism lower the odds of teenage pregnancy as compared to adherents of Roman Catholicism. While previous studies document that religion is associated with teenage pregnancy $(3,24,36)$, the specific mechanisms as to how different religious beliefs affect teenage pregnancy is not clear. Most religious belief systems in the Philippines consider premarital sex to be taboo and on one hand, there is evidence that increased religiosity delays sexual debut (37). On the other hand, evidence from the United States show that increased religiosity is associated with teenage pregnancy as more religious teens may be less likely to use contraception (36). One possible mechanism explaining this association is the respective belief systems' stand on contraceptive use. Roman Catholicism explicitly prohibits all forms of artificial contraception. On the contrary, Muslims are encouraged to use contraception but only within marriage as premarital sex is taboo in Islam. Protestant denominations adjust guidelines according to the circumstances of the woman and use of contraception is encouraged to prevent teenage pregnancy (37). The more encouraging stance of the latter religions might explain why their adherents have lower odds of teenage pregnancy.

The negative association between frequency of internet access and teenage pregnancy is not well-documented in published literature (38). Among studies in teenage pregnancy in the Philippines, this is the first time this association is demonstrated. One mechanism of action for this negative association is that more frequent internet access would expose people to information on effective contraception technologies and costs and difficulties of raising children. Another mechanism of action is that more frequent internet access would supplant face-to-face social interaction, reducing frequency of sexual intercourse, and therefore, birth rate. Analyses show that the rapid increase of internet coverage account for at least 13\% of the decline in birth rates between 1999-2007 in the United States (38). Thus, increasing internet

Page $11 / 15$ 
coverage can be considered as an intervention to reduce teenage pregnancies. Recent government and private sector investments in increasing internet access throughout the country $(39,40)$ may hopefully help decrease teenage pregnancies; however, such investments are only starting to be felt by the time the survey was conducted for it to have any meaningful effect in decreasing teenage pregnancy. Future research studying these associations should be conducted.

The tests for interaction are known for having low statistical power (41), which may explain the lack of joint effect between frequency of internet access and accessing contraceptive information via the internet. We were also unable to adjust for the effects of civil status and contraceptive use and intention, two known confounders in other studies (15-24), due to issues in separation and/or autocorrelation. Including such variables in the model might control for their possible confounding effect, but would affect the overall stability of the model by having unrealistic effect estimates and wide confidence intervals (47). For this reason, we excluded these two variables in multivariate analyses. In addition, this analysis has several other weaknesses. As compared to the analysis of the previous NDHS in the Philippines (15), this analysis included respondents aged 15-19, which means that the respondents are still at risk of developing the outcome, which may give an incomplete picture of the risk factors of teenage pregnancy. On the other hand, it may be argued that studying current teenagers minimizes issues on recall bias. Another possible weakness is residual confounding, especially that we were unable to control for many known confounders due to substantial missing data for these variables. Our prevalence of teenage pregnancy may also be an underestimate as we only had questions on currently pregnant and number of children, which means that those who had an abortion were not counted. Lastly, as the study used self-report data, the validity of its findings is as good as the information provided by the respondents.

\section{Conclusions}

Around $9 \%$ of respondents aged 15-19 have ever been pregnant. Coverage of dissemination of information of contraceptive use vary according to media; from $5 \%$ for SMS to $55 \%$ for television. Usage of modern contraceptive use remain low at around $2 \%$. After adjusting for confounding variables, there is evidence of a positive association between increasing age and having just primary education with teenage pregnancy. On the other hand, belonging to higher socio-economic strata, having frequent internet access, and being of the Protestant or Muslim faith lower the odds of teenage pregnancy. These highlight the need to strengthen reproductive health education and improve reproductive health awareness among the youth. However, recent evidence shows that reproductive health education per se might be insufficient in preventing teenage pregnancies and should be coupled with contraceptive-promoting interventions for it to be effective. Investments in internet coverage may also decrease teenage pregnancy and should be scaled up across many areas in the country. Urgent action is also needed considering that teenage pregnancies are on the rise as a result of the COVID-19 pandemic (48).

\section{Abbreviations}

$\mathrm{aOR}$

Adjusted odds ratio

HIV

Human Immunodeficiency Virus

NDHS

National Demographic and Health Survey

SMS

Short messaging service

\section{Declarations}

Ethics approval and consent to participate

The study has received ethics approval from the Ateneo de Manila University Research Ethics Committee (Protocol ID: SMPH DATA 2020).

$\underline{\text { Consent for publication }}$

Not applicable.

Availability of data and materials

The data for the 2017 Philippine National Demographic and Health Survey Individual Recode are available from the Demographic and Health Surveys Program Website (https://www.dhsprogram.com/data/available-datasets.cfm).

Competing interest

Page 12/15 
VCFP owns shares of GMA Network Inc., a Philippine Stock Exchange-listed company primarily involved in radio and television broadcasting. The other authors declare no competing interests.

\section{Funding}

This study is supported by the Ateneo de Manila University Research Council Standard Grant (Grant No.: 2020-01).

\section{$\underline{\text { Contributions }}$}

VCFP, AMLA, and LBST conceived the study. VCFP and AMLA performed the statistical analysis. VCFP, CST, NAKA, and LMBC wrote the first draft. AMLA, SJDLR, RSB, and LBST gave feedback and reviewed the drafts of the manuscript. All authors read and approved the final manuscript.

Acknowledgments

We thank the Demographic and Health Survey Program for allowing us to use their datasets to carry out this project.

\section{References}

1. Natividad J. Teenage Pregnancy in the Philippines: Trends, Correlates and Data Sources. J ASEAN Fed Endocr Soc. 2014 May 24;28(1):30.

2. Hussain R, Finer L. Unintended pregnancy and unsafe abortion in the Philippines: context and consequences [Internet]. Guttmacher Institute; 2013 [cited 2021 Apr 5]. Available from: https://www.guttmacher.org/sites/default/files/report_pdf/ib-unintended-pregnancyphilippines.pdf.

3. Melgar JLD, Melgar AR, Festin MPR, Hoopes AJ, Chandra-Mouli V. Assessment of country policies affecting reproductive health for adolescents in the Philippines. Reprod Health. 2018 Dec 12;15(1):205.

4. Ganchimeg T, Ota E, Morisaki N, Laopaiboon M, Lumbiganon P, Zhang J, et al. Pregnancy and childbirth outcomes among adolescent mothers: a World Health Organization multicountry study. BJOG Int J Obstet Gynaecol. 2014 Mar;121(Suppl 1):40-8.

5. Chen X-K, Wen SW, Fleming N, Demissie K, Rhoads GG, Walker M. Teenage pregnancy and adverse birth outcomes: a large population based retrospective cohort study. Int J Epidemiol. 2007 Apr;36(2):368-73.

6. Kurth F, Bélard S, Mombo-Ngoma G, Schuster K, Adegnika AA, Bouyou-Akotet MK, et al. Adolescence As Risk Factor for Adverse Pregnancy Outcome in Central Africa - A Cross-Sectional Study. PLOS ONE. 2010 Dec;20(12):e14367. 5(.

7. Raj A, Boehmer U. Girl child marriage and its association with national rates of HIV, maternal health, and infant mortality across 97 countries. Violence Women. 2013 Apr;19(4):536-51.

8. World Health Organization, UNAIDS. Global standards for quality healthcare services for adolescents [Internet]. WHO. World Health Organization; 2015 [cited 2021 Apr 5]. Available from: http://www.who.int/maternal_child_adolescent/documents/global-standardsadolescent-care/en/.

9. Adolescent pregnancy [Internet]. [cited 2021 Apr 4]. Available from: https://www.who.int/news-room/fact-sheets/detail/adolescentpregnancy.

10. Philippine Statistics Authority (PSA). ICF International. National Demographic and Health Survey (Philippines) 2013.2014.

11. United Nations Population Fund. \#GirlsNotMoms: Eliminating Teenage Pregnancy in the Philippines [Internet]. 2020 [cited 2021 Mar 22]. Available from: https://philippines.unfpa.org/sites/default/files/pub-pdf/UNFPA_Policy_Brief_Teenage_Pregnancy_\%282020-0124\%29.pdf.

12. Philippine Statistics Authority (PSA), ICF. Philippine National Demographic and Health Survey 2017 [Internet]. PSA and ICF; 2018. Available from: https://psa.gov.ph/sites/default/files/PHILIPPINE\%20NATIONAL\%20DEMOGRAPHIC\%20AND\%20HEALTH\%20SURVEY\%202017_new.pdf.

13. Republic Act No. 10354 [Internet]. Official Gazette of the Republic of the Philippines. 2012 [cited 2021 Mar 21]. Available from: https://www.officialgazette.gov.ph/2012/12/21/republic-act-no-10354/.

14. Maravilla JC, Betts KS, Alati R. Trends in repeated pregnancy among adolescents in the Philippines from 1993 to 2013. Reprod Health. 2018 Nov 6;15(1):184

15. Habito CM, Vaughan C, Morgan A. Adolescent sexual initiation and pregnancy: what more can be learned through further analysis of the demographic and health surveys in the Philippines? BMC Public Health. 2019 Aug 20;19(1):1142.

16. Donatus L, Sama DJ, Tsoka-Gwegweni JM, Cumber SN. Factors associated with adolescent school girl's pregnancy in Kumbo East Health District North West region Cameroon. Pan Afr Med J [Internet]. 2018 Oct 25 [cited 2021 Apr 5];31(138). Available from: 
https://www.panafrican-med-journal.com/content/article/31/138/full.

17. Ayele BG, Gebregzabher TG, Hailu TT, Assefa BA. Determinants of teenage pregnancy in Degua Tembien District, Tigray, Northern Ethiopia: A community-based case-control study. PLoS ONE [Internet]. 2018 Jul 25 [cited 2021 Apr 5];13(7). Available from: https://www.ncbi.nlm.nih.gov/pmc/articles/PMC6059451/.

18. Ayanaw Habitu Y, Yalew A, Azale Bisetegn T Prevalence and Factors Associated with Teenage Pregnancy, Northeast Ethiopia, 2017: A Cross-Sectional Study. J Pregnancy. 2018 Nov 1;2018:e1714527.

19. Mezmur H, Assefa N, Alemayehu T. Teenage Pregnancy and Its Associated Factors in Eastern Ethiopia: A Community-Based Study. Int J Womens Health. 2021 Feb 26;13:267-78.

20. Wall-Wieler E, Roos LL, Nickel NC. Teenage pregnancy: the impact of maternal adolescent childbearing and older sister's teenage pregnancy on a younger sister. BMC Pregnancy Childbirth. 2016 May 25;16(1):120.

21. McCall SJ, Bhattacharya S, Okpo E, Macfarlane GJ. Evaluating the social determinants of teenage pregnancy: a temporal analysis using a UK obstetric database from 1950 to 2010. J Epidemiol Community Health. 2015 Jan 1;69(1):49-54.

22. Sychareun V, Vongxay V, Houaboun S, Thammavongsa V, Phummavongsa P, Chaleunvong K, et al. Determinants of adolescent pregnancy and access to reproductive and sexual health services for married and unmarried adolescents in rural Lao PDR: a qualitative study. BMC Pregnancy Childbirth. 2018 Jun 8;18(1):219.

23. Yakubu I, Salisu WJ. Determinants of adolescent pregnancy in sub-Saharan Africa: a systematic review. Reprod Health. 2018 Jan 27;15(1):15.

24. Mutshaeni NH, Malovhele PT, Mashau ST, Manwadu LR. A Min Literature on the Determinants of Teenage Pregnancy: Intrapersonal and Interpersonal Factors. Stud Ethno-Med. 2016 Oct;10(4):472-80.

25. Maravilla JC, Betts KS, Alati R. Exploring the Risks of Repeated Pregnancy Among Adolescents and Young Women in the Philippines. Matern Child Health J. 2019 Jul;23(7):934-42.

26. Executive Order No. 12, s. 2017 [Internet]. Official Gazette of the Republic of the Philippines. 2017 [cited 2021 Mar 21 ]. Available from: https://www.officialgazette.gov.ph/2017/01/09/executive-order-no-12-s-2017/.

27. Gonzales C. PopCom clarifies: Teen pregnancy rate much worse [Internet]. INQUIRER.net. 2020 [cited 2021 Apr 5]. Available from: https://newsinfo.inquirer.net/1337228/popcom-clarifies-teen-pregnancy-rate-much-worse.

28. StataCorp. Stata 14.0 IC. College Station: StataCorp; 2015.

29. Rothman KJ. No adjustments are needed for multiple comparisons. Epidemiol Camb Mass. 1990 Jan;1(1):43-6.

30. Cabral E. Reproductive Health Law in the Philippines. J ASEAN Fed Endocr Soc. 2013;28(1):26-6.

31. VanderWeele TJ. Principles of confounder selection. Eur J Epidemiol. 2019 Mar 1;34(3):211-9.

32. Population Commission (Region VIII. Philippines). RPRH - Education for Adolescents [Internet]. [cited 2021 May 23]. Available from: https://rpo8.popcom.gov.ph/rprh-education-for-adolescents/.

33. Department of Education (Philippines). Policy guidelines on the implementation of the comprehensive sexuality education [Internet]. 2018 [cited 2021 May 23]. Available from: https://www.deped.gov.ph/wp-content/uploads/2018/07/D0_s2018_031-1.pdf.

34. Mwaikambo L. Comprehensive Sexuality Education | The Challenge Initiative [Internet]. [cited 2021 May 23]. Available from: https://tciurbanhealth.org/courses/philippines-toolkit-community-support/lessons/comprehensive-sexuality-education-2/.

35. Oringanje C, Meremikwu MM, Eko H, Esu E, Meremikwu A, Ehiri JE. Interventions for preventing unintended pregnancies among adolescents. Cochrane Database Syst Rev [Internet]. 2016 [cited 2021 May 24];(2). Available from: https://www.cochranelibrary.com/cdsr/doi/10.1002/14651858.CD005215.pub3/full.

36. Strayhorn JM, Strayhorn JC. Religiosity and teen birth rate in the United States. Reprod Health. 2009 Sep 17;6(1):14.

37. Ottenbacher M. Religion Predicting Fertility Behaviour of Young Women in Contemporary Germany [Internet]. Universitat Trier; Available from: https://www.uni-trier.de/fileadmin/fb4/prof/VWL/EWF/Research_Papers/2020-07.pdf.

38. Guldi M, Herbst CM. Offline effects of online connecting: the impact of broadband diffusion on teen fertility decisions. J Popul Econ. 2017 Jan;30(1):69-91.

39. Republic Act 10929 - Free Internet Access Program in Public Places [Internet]. Available from: https://www.officialgazette.gov.ph/2017/08/02/republic-act-no-10929/.

40. Philippines. average internet connection speed 2017 | Statista [Internet]. [cited 2021 Aug 7]. Available from: https://www.statista.com/statistics/714150/average-internet-connection-speed-in-the-philippines/.

41. Marshall SW. Power for tests of interaction: effect of raising the Type I error rate. Epidemiol Perspect Innov EPI. 2007 Jun;19:4:4.

42. Ahinkorah BO, Kang M, Perry L, Brooks F, Hayen A. Prevalence of first adolescent pregnancy and its associated factors in sub-Saharan Africa: A multi-country analysis. PLOS ONE. 2021 Feb;4(2):e0246308. 16(. 
43. Iyanda AE, Dinkins BJ, Osayomi T, Adeusi TJ, Lu Y, Oppong JR. Fertility knowledge, contraceptive use and unintentional pregnancy in 29 African countries: a cross-sectional study. Int J Public Health. 2020 May 1;65(4):445-55.

44. Guzzo KB, Hayford SR. Adolescent Reproductive and Contraceptive Knowledge and Attitudes and Adult Contraceptive Behavior. Matern Child Health J. 2018 Jan;22(1):32-40.

45. Ajayi Al, Ismail KO, Akpan W. Factors associated with consistent condom use: a cross-sectional survey of two Nigerian universities. BMC Public Health. 2019 Sep 2;19(1):1207.

46. United Nations Population Fund, World Health Organization, Joint United Nations Program on HIV/AIDS. UNFPA, WHO and UNAIDS: Position statement on condoms and the prevention of HIV, other sexually transmitted infections and unintended pregnancy [Internet]. WHO. World Health Organization; 2015 [cited 2021 Mar 22]. Available from: https://www.who.int/hiv/mediacentre/news/condoms-jointpositionpaper/en/.

47. Mansournia MA, Geroldinger A, Greenland S, Heinze G. Separation in Logistic Regression: Causes, Consequences, and Control. Am J Epidemiol. 2018 Apr 1;187(4):864-70.

48. Pazzibugan DZ. Teen pregnancies could rise during pandemic - Popcom [Internet]. INQUIRER.net. 2021 [cited 2021 May 24 ]. Available from: https://newsinfo.inquirer.net/1394522/popcom-covid-curbs-could-worsen-teen-pregnancies. 